\title{
Investigating the Effect of Telenursing on Health Promoting Behaviours of Haemodialysis Patients in Education Hospitals in Zahedan in 2017-2018
}

\author{
Alireza Shahsavani ${ }^{1}$, Fatemeh Kiani ${ }^{2}$ \\ ${ }^{1}$ Community Nursing Research Center, Zahedan University of Medical Sciences, Zahedan, Iran. \\ ${ }^{2}$ Community Nursing Research Center, Zahedan University of Medical Sciences, Zahedan, Iran.
}

\section{ABSTRACT}

\section{BACKGROUND}

The main goal of treatment and care of chronic patients including patients with chronic kidney failure undergoing haemodialysis is to promote their health. This study has been performed with the aim of examining the effect of tele-nursing on health promoting behaviours of haemodialysis patients in educational hospitals of Zahedan city in 2017-2018.

\section{METHODS}

This quasi-experimental study was performed on patients undergoing haemodialysis who qualified the inclusion criteria. The number of participants in this study was 60 (30 in the intervention group and 30 in the control group) chosen through available sampling and then random allocation. For data collection, health promotion standard questionnaire was used. After beginning the intervention and implementing educational programs in three sessions, the patients in the intervention group had telephone follow-up for 12 weeks.

\section{RESULTS}

The mean and standard deviation of agent in the intervention and control group were as follows: $\bar{x}=44.56$ and $S D=10.59 ; \bar{x}=42.3$ and $S D=11.56$, respectively. The mean scores of different areas of the health promotion questionnaire before and after the intervention in the two groups using paired t-test and Lewin indicated that in the dimensions of exercise ( $p$ value $=0.002)$, stress ( $p$ value $=0.01)$, interpersonal relationships ( $p$ value $=0.006)$, and responsibility $(p$ value $=0.006)$ were significant, but it was insignificant in the dimensions of nutrition and spiritual growth.

\section{CONCLUSIONS}

Since health behaviours had been promoted in the intervention group as compared to the control group, it can be thus concluded that with proper policymaking and planning in employing telephone follow-up, one can promote health behaviours and take steps to properly plan for improving the health status of patients.

\section{KEY WORDS}

Telenursing, Health Promoting Behaviours, Haemodialysis Patients

\author{
Corresponding Author: \\ Fatemeh Kiani, \\ Community Nursing Research Center \\ Zahedan University of Medical Sciences, \\ Zahedan, Iran. \\ E-mail: hadismast@gmail.com
}

DOI: $10.14260 /$ jemds/2019/722

Financial or Other Competing Interests: None.

How to Cite This Article:

Shahsavani A, Kiani F. Investigating the effect of telenursing on health promoting behaviours of haemodialysis patients in education hospitals in Zahedan in 20172018. J. Evolution Med. Dent. Sci. 2019;8(44):3326-3331, $10.14260 /$ jemds $/ 2019 / 722$

Submission 29-06-2019, Peer Review 17-10-2019, Acceptance 23-10-2019, Published 04-11-2019. 


\section{BACKGROUND}

Today, with increased life expectancy, chronic diseases have emerged as a major health problem. These long-term and debilitating diseases with incurable pathology are responsible for $60 \%$ of mortalities worldwide.(1) Chronic kidney failure disease is one of these conditions causing the person to play the role of a patient throughout their entire lives due to their health and disease conditions.(2) Based on statistics, the prevalence of chronic kidney failure in the world is 260 cases per every 1 million population annually, which grows by around 6\% every year.(3) According to scientific statistics of health ministry, this disease annually grows by $20 \%$ in Iran.(4) Meanwhile, there are over 18,000 patients undergoing haemodialysis in the country.(5) Different methods are proposed for treating patients with chronic kidney failure, where one of the most effective and common is haemodialysis. Although haemodialysis increases the longevity of patients with kidney failure, it brings about various problems.(6) Haemodialysis, as part of the course of treating a chronic disease, can result in alteration of lifestyle, health status, and playing one's social roles. In addition, it increases the healthcare services and undermines the quality of life of patients. $(7,8)$ Haemodialysis can lead to considerable changes in the life of these patients including diminished efficiency and ability for activities, weakness, fatigue, social isolation, immobility, diminished self-confidence, and eventually loss of hope towards the future. Existence of these conditions compromises the health status and personal roles, thereby reducing the quality of life of patients. The various problems resulting from the therapeutic course and the longterm dependence of the person on haemodialysis highlighted the necessity of paying attention to the quality of life of these patients.(9) Various solutions have been proposed for improving the quality of life of patients with chronic diseases, one of which is health promoting behaviours. $(10,11)$

Health promoting behaviours are one of the major criteria for determining the health, which has been known as an underlying factor in not catching many diseases. Also, promoting the health and preventing diseases are directly associated with these behaviours.(12) Practicing health promoting behaviours is one of the best methods people can use to preserve and control their health.(13) Health promotion refers to the science and art of altering the lifestyle to achieve the desirable perfection. Among the factors associated with healthy and unhealthy behaviours, one can mention demographic factors such as age, gender, marital status, and economic level.(14) Health promotion covers behaviours through which the person adheres to proper nutrition, regular exercise, refraining from damaging behaviours and drugs of abuse, protection against accidents, timely diagnosis of disease symptoms in physical dimension, controlling emotions and feelings as well as thoughts and coping with stress and problems in the psychological dimension, independence and adaptation, along with modifying interpersonal relationships in the social dimension.(15)

In spite of the increase in methods for treatment and advances in the technology in the developing and constantly changing world, inability in achieving the desired target in the management of a disease is an important issue for healthcare providers. Furthermore, it is highly recommended that the patient themselves try to manage their disease and improvement in order to be empowered against chronic diseases, which is a widely established approach.(16) Telenursing technology has been defined as a means for enhancing support in self-care and regulating the patient access to medical services, which is rapidly developing in many countries.(17) Many previous studies in this area suggested the commitment of the contactor person to presenting proper nursing care and expression of satisfaction of patients toward the high quality of these services.(18) So far, traditional methods of patient training have been used (Faceto-face training, lecture, educational pamphlet, etc.). Considering the advances in technology, it seems that usage of new technology could be able to transform patient training. The convenience of patient access and responding to their questions provide the proper conditions for training where patients can benefit from nursing recommendations. Through phone contact, the patient and their families will be able to find the answer of many questions they have in mind at home. On the other hand, the problems of patient commuting to and from healthcare centers for response to some part of healthcare measures will also diminish. This method would also be able to reduce the costs incurred to the patients. Furthermore, there is no need to spend time for direct referral to healthcare centers.(19) According to what has been mentioned above, the nurse should look at this technology as a means of care, yet they should not regard it as an alternative means for high quality nursing function. The security of the patient is accomplished when the nurse focuses on patient care not the technology itself. Therefore, considering the necessity of this issue that treatment with remote communication methods can have a great impact on shortening the course of improvement of chronic diseases such as kidney failure and reducing costs and the patient's need to constant access to hospital and healthcare centers and as the importance of this issue in the world and Iran has remained understudied and regarding the importance of monitoring the course of disease in individuals hospitalized in the haemodialysis ward of hospitals, we decided to implement this interventional plan in educational hospitals of Zahedan city. This study has been performed with the aim of examining the effect of tele-nursing on health promoting behaviours of haemodialysis patients in educational hospitals of Zahedan city in 2017-2018.

\section{METHODS}

This was a quasi-experimental study, sample size consisted of all patients undergoing haemodialysis in Imam Ali and Khatam Alanbai educational hospitals in Zahedan city, in 2018. The present study was approved by Institutional review board and Ethics Committee of Zahedan University of Medical Science (Ethic code: IR.ZAUMS.REC.1396.96). Written and oral informed consents were obtained from all participants. Sampling method was convenience, each group had at least 30 patients. First all patient's lists were taken from the related hospitals, those that had entrance criteria were distinguished. Then patients were divided in two 
groups by simple random method using table of random numbers.

Sample size and power were predicted based on the number of newly diagnosed ERDS patients admitted to the study hospital in $2018(\mathrm{~N}=25)$. We anticipated that around 60 ERDS patients would be admitted to the hospital in the study period. A power analysis was calculated based on the number of participants expected to complete the study, not the number recruited initially. For 50\% difference in the proportion of subjects with a health status score $\geq 10$ (Cut-off score) between the two groups, 25 subjects per group was required to reach a power level of.90 for an alpha level of.05 (Two-sided test). To compensate for an expected attrition rate of $20 \%$, we aimed to recruit 30 subjects in each group (total of 60 subjects).

In terms of age and gender. For data collection, Walker et al. (1987) health promoting lifestyle standard questionnaire was used.(20) This questionnaire measures health promoting behaviours in six dimensions (Nutrition, exercise, responsibility about health, stress management, interpersonal support, and self-actualization). This questionnaire has been used frequently in Iran, and the Cronbach alpha coefficient was determined by Mohammadi et al. as 0.82 , and for each of the subscales in six areas it was determined as 0.64-0.91. For inclusion into the study, the patients had 20 to 60 years of age and all of them had ESRD, who had constant and regular referral for 12 weeks and three times per week for dialysis. Furthermore, when choosing the patients, care was applied so that none of them would have neurological or muscular disorders, psychiatric disorders, or malignancy or haematological diseases. All of them had been undergoing haemodialysis for at least three months, and the patients who had kidney transplant or their course of treatment had changed into peritoneal dialysis and did not comply with the treatment plan were excluded from the study. Selection of the samples was performed according to inclusion criteria. If the patients were literate, the forms were completed based on the explanations of the researcher, while for illiterate patients, their information was taken by reading the questionnaire questions by the researcher. Thereafter, the patients were segregated into two groups through simple using table of random numbers. Once the samples were chosen randomly and before the educational sessions, pretest was administered. For the patients in the intervention group, the procedure of implementation was trained in group in three 1-h sessions before dialysis. Furthermore, before, during, and after dialysis in the first week of sampling, personal education was also provided to the patients. After this stage, the intervention was performed on the experimental group for 12 weeks. Specifically, phone contacts were established to follow up compliance with the dialysis diet, exercise, responsibility about health, stress management, interpersonal support, and self-actualization in the first month twice per week, and in the second and third months once a week with the subjects in the intervention group. The duration of conversation was considered 10 minutes on average. The time of phone contact was determined as between $8 \mathrm{AM}$ to $8 \mathrm{PM}$ according to agreement with patients. The content of conversations included assessment of compliance of the subjects with the dialysis diet, exercise, responsibility about health, stress management, interpersonal support, and actualization. In case of lack of compliance, the situation was analysed with the help of the person to find the problem and eventually present a solution and respond to the possible questions of the patients. Further, in each phone conversation session, the content of conversation was recorded in a pre-set form. Note that during the intervention, the control group underwent no interventions by the researchers. After implementing the intervention, health promoting questionnaires were given again to both intervention and control groups. At the end, a comprehensive educational pamphlet was given to the control group. (Figure 1)

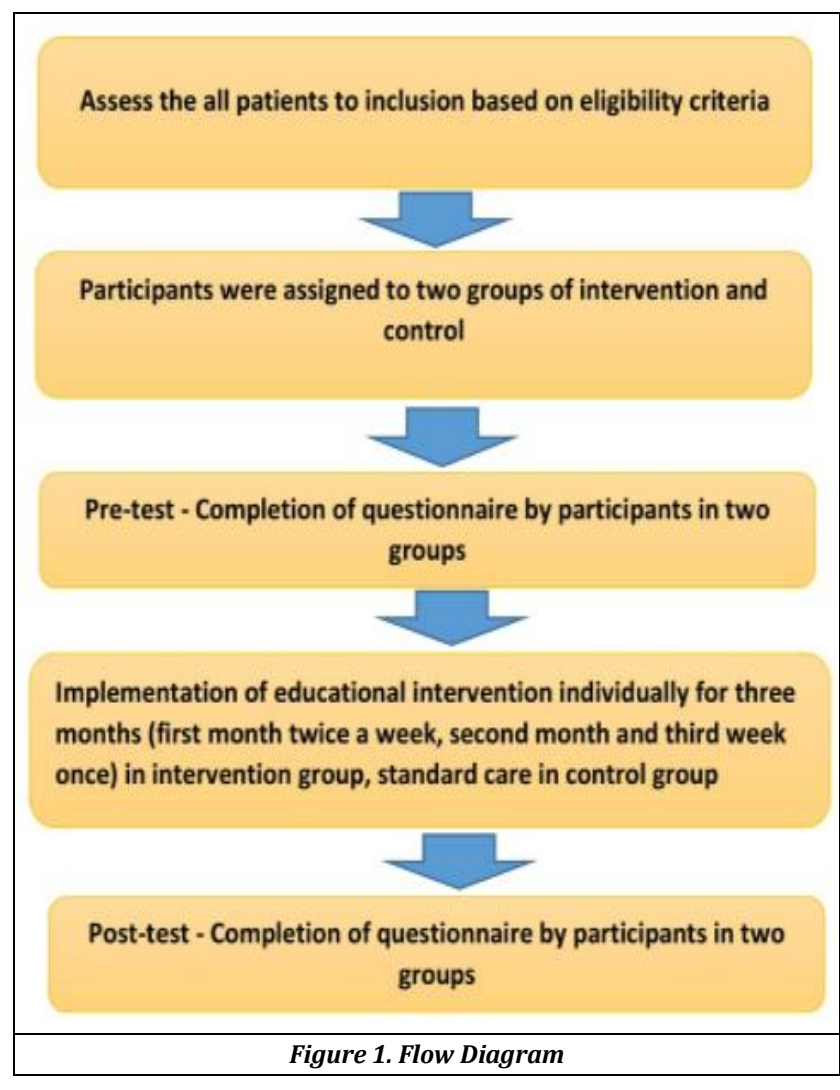

\section{Statistical Analysis}

The data were introduced into SPSS 21. To describe the demographic characteristics, descriptive tests (Percentage, frequency and mean) were used. An independent t-test were used to interprets the results. The relationship between telenursing follow-up and health promoting behaviours in patients was examined using relevant statistical tests and the results were reported.

\section{RESULTS}

In this research, 60 patients undergoing haemodialysis were studied. The patients were allocated to two groups: 30 in intervention and 30 in control groups. In terms of gender, $36.7 \%(n=22)$ were women and $63.3 \%(n=38)$ were men. Concerning marital status, $83.3 \%$ were married, $13.3 \%$ were single, and around $3.3 \%$ were divorced. In terms of 
occupation, $30 \%$ were unemployed, $25 \%$ housewife, and only $15 \%$ were employee. The educational level of patients in both groups showed that most patients $30 \%$ were illiterate and only $10 \%$ had bachelor's degree and above. Also, the mean age in the intervention group was $\bar{x}=44.56$ and $S D=10.59$, and in the control group, they were $\bar{x}=42.3$ and $S D=11.56$. (Table 1).

\begin{tabular}{|c|c|c|}
\hline Variable & Percentage & Frequency \\
\hline Gender & & \\
Male & $63.3 \%$ & 38 \\
Female & $36.7 \%$ & 22 \\
\hline Marital status married & $83.3 \%$ & 50 \\
Single & $13.3 \%$ & 8 \\
Divorced & $3.3 \%$ & 2 \\
\hline Level of education & $30 \%$ & 18 \\
Illiterate & $21.7 \%$ & 13 \\
Primary guidance & $13.3 \%$ & 13 \\
High school & $5 \%$ & 8 \\
Diploma and associate degree & $20 \%$ & 3 \\
Bachelor's and master's & $10 \%$ & 12 \\
\hline Occupational status & $30 \%$ & 18 \\
Unemployed & $25 \%$ & 15 \\
Housewife & $25 \%$ & 15 \\
Freelancer & $15 \%$ & 9 \\
Employee & $5 \%$ & 3 \\
Other & Table 1. Demographic Characteristics of Patients \\
\hline
\end{tabular}

The mean scores of areas of the health promotion behaviours before the intervention in the two groups using independent t-test and Lewin test indicated that in the control and intervention groups, the maximum mean was related to the dimension of responsibility with the values of 40.8 and 36.9, respectively, while the minimum was associated with the dimension of exercise with 11 and 11.4, respectively.

The mean scores of areas of the health promoting questionnaire after the intervention were also captured using independent $\mathrm{t}$-test and Lewin test. The obtained results indicated that in the dimension of interpersonal relationships, after the intervention and in comparison to pre-intervention, the values were significant, where independent t-test and Lewin test showed that the mean score of interpersonal relations dimension in the intervention group was 24.5 , while this mean before intervention was 23.6. On the other hand, in the control group before and after the intervention, the values were 21.1 and 21.7 , respectively, which showed no significant difference.

The results showed that comparison of the scores of areas of the health promotion questionnaire before and after the intervention in the two intervention groups using paired ttest and Lewin test indicated that in the dimensions of exercise ( $p$ value $=0.002)$, stress $(p=0.01)$, interpersonal relationships $(p=0.006)$, and responsibility $(p=0.06)$ it was significant, but in the dimensions of nutrition and spiritual growth it was not significant.

The results in Table 2 indicate that comparison of the scores of the areas of the health promotion behaviour before and after the intervention in the two groups via independent t-test indicated that in the dimension of nutrition, the difference between the intervention and control groups was nonsignificant with $\bar{x}=0.16$ and $S D=1.6$. However, in the dimension of exercise, it was significant with $\bar{x}=1$ and $S D=1.5$
Further, in the dimension of the stress management, the results of statistical tests indicated that the mean score before the intervention was 0.76 and SD was 7.2 , where $p$ value $=0.009$, suggested that it was significant.

In the dimension of responsibility of health promotion, the results showed that $\bar{x}=3$ and $\mathrm{SD}=3.3$ the difference was significant with $\mathrm{p}$ value $=0.002$. In the dimension of spiritual growth, $\bar{x}=0.66$ and $\mathrm{SD}=2.5$. (Table 2 ).

\begin{tabular}{|c|c|c|c|c|}
\hline & Group & Mean & S.D. & p \\
\hline \multirow{2}{*}{$\begin{array}{l}\text { Difference of nutrition dimension of } \\
\text { health promotion }\end{array}$} & intervention & .1667 & 1.57750 & .474 \\
\hline & control & -.2000 & 1.24291 & \\
\hline \multirow{2}{*}{$\begin{array}{l}\text { Difference of exercise dimension of } \\
\text { health promotion }\end{array}$} & intervention & 1.0000 & 1.59741 & .001 \\
\hline & cont & .1667 & .83391 & \\
\hline \multirow{2}{*}{$\begin{array}{l}\text { Difference of stress management } \\
\text { dimension of health promotion }\end{array}$} & intervention & .7667 & 1.61210 & .009 \\
\hline & cont & -.3000 & 1.08755 & \\
\hline \multirow{2}{*}{$\begin{array}{l}\text { Difference of interpersonal relations } \\
\text { dimension of health promotion }\end{array}$} & intervention & .9667 & 1.77110 & .578 \\
\hline & con & .5667 & 1.43078 & \\
\hline \multirow{2}{*}{$\begin{array}{c}\text { Difference of responsibility } \\
\text { dimension of health promotion }\end{array}$} & interv & 3.0667 & 3.32 & .002 \\
\hline & & .8667 & 1.90703 & \\
\hline \multirow{2}{*}{$\begin{array}{l}\text { Difference in spiritual growth } \\
\text { dimension of health promotion }\end{array}$} & $\begin{array}{c}\text { Intervention } \\
\text { control }\end{array}$ & .6667 & 2.59088 & .341 \\
\hline & & -.2667 & 1.70057 & \\
\hline
\end{tabular}

Table 2. Comparison of Difference of Scores of Different Areas of Health Promotion Questionnaire Before and After the Intervention in the Two Groups with Independent T-Test plus Lewin Test

\section{DISCUSSION}

The results of the present study indicated that after the intervention, the mean scores of the six areas of health promotion were significant except for spiritual growth and nutrition. This means that educational intervention followed by telephone follow-up (Tele-nursing) has resulted in improved health promotion of patients in four dimensions out of six dimensions of health promotion. The results of the present study have been congruent with the findings of Kamrani et al. entitled "examining the effect of patient training and telephone follow-up (Tele-nursing) by the nurse on compliance with diet for patients with acute coronary syndrome."(21) They found that patient training and telephone follow-up both are effective in improving compliance with the diet. Nevertheless, the patients in the training group and telephone follow-up had greater compliance with the diet in comparison to the education. The researchers suggested that telephone follow-up should be used to provide services to patients. (21)

Further, the results of the present study have been in line with the findings of Shoijaei et al. (2013) who examined the effect of patient training on telephone follow-up on readmission of patients with heart failure.(22)

The results of the study by Shojaei et al. indicated that the rate of readmission was higher in the patients of control group than in the training group. Also, in the group of patients in which the patients had both educational pamphlet and telephone follow-up, the readmission rate was lower in comparison to the training alone group. ${ }^{(22)}$

In the study by Fakharzadeh et al. entitled "investigating the effect of tele-nursing on glycosylated haemoglobin and anthropometric indicators in type II diabetes patients", they found that the mean glycosylated haemoglobin and body mass index significantly decreased after the intervention in the case group as compared to the preintervention $(p<0.05)$. However, in the control group, no significant difference was observed.(23) 
At the end, the researchers concluded that tele-nursing as a preventive method can cause improved glycemia of patients.(24) Also, the review study by Kotb et al. (2014) testing the extent of compliance with treatment in patients with coronary artery disease, also confirmed the results of the present study. They found that telephone follow-up resulted in diminished rehospitalization of patients in hospital as well as reduced systolic blood pressure and depression.(24)

The results of a study by Behzad et al. (2015) entitled the effect of empowerment program (self-care workshop) based on telephone follow-up (Tele-nursing) emphasized selfefficacy in promoting self-efficacy in self-care behaviours of the elderly with hypertension.(25)

In the study by Boraz et al. entitled "comparing the effect of in person and distance education of self-care on the quality of life and physical problems of patients undergoing haemodialysis maintenance therapy, they found that most of the studied variables including laboratory tests, blood pressure, weight gain between two sessions of dialysis, pruritus, oedema, and warmness of the vascular pathway in each of the groups of in person and distant education, changed significantly before and after the education. It seems that concerning the problems and costliness of the in person educational method in comparison to distant education, the latter is recommended as an effective, inexpensive, simple, and attractive method for patients undergoing haemodialysis.(26) Although in the study by Bozar et al., distant education was emphasized, in a number of studies such as the one by Wang et al. (2013), concerning the effect of visiting the home and telephone follow-up on post discharge educations and rehospitalization of patients, it was found that telephone follow-up alone may not be effective in reducing the rehospitalization of patients, and it is necessary that several methods be concurrently used for post discharge education.(27)

In the present study, in addition to education followed by telephone follow-up for 12 weeks, for greater effectiveness of trainings, educational pamphlets have been also used. It also seems that tele-nursing is more effective when before followup of patients, it is better that complete education of patients is performed through educational pamphlets or other instruments. These results suggest that telephone follow-up plays a significant role in health promoting behaviours of haemodialysis patients, and enhancing awareness and creating sensitivity in patients cause them to have active participation in the treatment process and be successful in controlling their disease.

The general view in controlling chronic diseases focuses on strengthening and involving the patient in the decisionmaking process. Although the treatment team presents the care program to the patient, this is the patient themselves who should apply health promoting behaviours. To cope with their disease and for learning to change their lifestyle, patients need time as well as constant monitoring of their abilities in health promoting affairs and behaviours. Therefore, follow-up with the aim of establishing and creating an effective and dynamic care relation seems to be essential to enhance the awareness and health promoting behaviours. Therefore, it can be concluded that the changes developed in the test group have been due to intervention induce research, i.e. telephone follow-up (Tele-nursing) for this group. In other words, regular follow-up and its continuity following the education managed to improve health promoting behaviours in the test group compared to the control group more significantly than in the control group. It can be stated that follow-up as in person referral of patient will be more expensive and time-consuming in comparison to telephone follow-up. It is also possible that the patient may not refer for the follow-up sessions. With telephone follow-up, first the patient understands the importance of health promoting behaviours, and their sensitivity for enhancing their health level increases. In the present study, all of the studied individuals in the case and control groups underwent the education of health promoting behaviours. However, the changes were greater in the intervention group than in the control group. It can be concluded that, the changes developed in the case group have been due to telephone follow-up.

\section{CONCLUSIONS}

By incorporating the necessary policies and plans for applying telephone follow-up, one can take measures for health promoting behaviours to effectively control this disorder and help haemodialysis patients. it also helps in reducing the rate of frequent referral to hospital in the healthcare system. It further results in decreased waste of time and costs incurred to both the healthcare system and patient. Provision of services through tele-nursing and telephone follow-up in support programs, health promoting behaviours for haemodialysis patients are recommended.

\section{ACKNOWLEDGEMENT}

The authors of this paper highly appreciate the research committee of Zahedan University of Medical Sciences for registering the paper as well as the Head of Aliebne Abitaleb and Khatam Alanbia Hospitals of Zahedan, the authorities, nurses, staff, and patients of haemodialysis wards who helped us in data collection. This study has been registered in the Iranian Clinical Trial Registration Center with the code IRCT20171009036675N1.

\section{REFERENCES}

[1] Clark NM, Gong M, Kaciroti N. A model of self-regulation for control of chronic disease. Health Education \& Behavior 2001;28(6):769-82.

[2] Baigent C, Landray MJ, Reith C, et al. The effects of lowering LDL cholesterol with simvastatin plus ezetimibe in patients with chronic kidney disease (Study of Heart and Renal Protection): a randomised placebocontrolled trial. The Lancet 2011;377(9784):2181-92.

[3] Collins AJ, Foley RN, Chavers B, et al. United States Renal Data System 2011 Annual Data Report: Atlas of chronic kidney disease \& end stage renal disease in the United States. Am J Kidney Dis 2012;59(1 Suppl 1):A7, e1-420. 
[4] Schatell D. A paradigm shift in options, education and an online decision aid: 'My Life, My Dialysis Choice'. Nephrology Nursing Journal 2015;42(2):149-53.

[5] Omrani $\mathrm{KH}$, Shafiee $\mathrm{M}$, Safari $\mathrm{H}$, et al. Equity in geographical distribution of dialysis beds and nephrologists based on the Lorenz curve and gini coefficient need indices: case of Iran. 2013.

[6] Anees M, Hameed F, Mumtaz A, et al. Dialysis-related factors affecting quality of life in patients on haemodialysis. Iranian Journal of Kidney Diseases 2011;5(1):9-14.

[7] McKean SC. Principles and practice of hospital medicine: Univerza v Ljubljani, Medicinska fakulteta 2012.

[8] Viefhues H, Schoene W, Rychlik R, et al. Chronic heart failure: I. Quality of life. II. Nitrate therapy. Springer Science \& Business Media 2012.

[9] Rayner HC, Zepel L, Fuller DS, et al. Recovery time, quality of life and mortality in haemodialysis patients: the Dialysis Outcomes and Practice Patterns Study (DOPPS). American Journal of Kidney Diseases 2014;64(1):86-94.

[10] Van Achterberg T, Huisman-de Waal GG, Ketelaar NA, et al. How to promote healthy behaviours in patients? An overview of evidence for behaviour change techniques. Health Promotion International 2010;26(2):148-62.

[11] Ma LC, Chang HJ, Liu YM, et al. The relationship between health-promoting behaviours and resilience in patients with chronic kidney disease. Article ID 124973, The Scientific World Journal 2013;2013: p. 7.

[12] Shaban M, Mehran A, Taghlili F. Relationship between perception of health concept and health promoting behaviours: a comparative study among Tehran university medical and non-medical students. Journal of Hayat 2007;13(3):27-36.

[13] Díez USM, Perez-Fortis A. Socio-demographic predictors of health behaviours in Mexican college students. Health Promotion International 2010;25(1):85-93.

[14] Chamroonsawasdi K, Phoolphoklang S, Nanthamongkolchai $\mathrm{S}$, et al. Factors influencing health promoting behaviours among the elderly under the universal coverage program, Buriram Province, Thailand. Asia Journal of Public Health 2010;1(1):15-9.

[15] Darvishpoor KA, Ebrahim H, Hamid AM. Health status of nurses of hospitals dependent to Shahroud Medical University. Iran journal of Nursing 2009;22(60):19-27.

[16] Celik S, Cosansu G, Erdogan S, et al. Using mobile phone text messages to improve insulin injection technique and glycaemic control in patients with diabetes mellitus: a multi-centre study in Turkey. Journal of Clinical Nursing 2015;24(11-12):1525-33.
[17] Timpka T, Spreco A, Eriksson 0, et al. Predictive performance of telenursing complaints in influenza surveillance: a prospective cohort study in Sweden. Eurosurveillance 2014;19(46): pii. 20966.

[18] Turbitt E, Freed GL. Use of a telenursing triage service by Victorian parents attending the emergency department for their child's lower urgency condition. Emergency Medicine Australasia 2015;27(6):558-62.

[19] Barkley TW, Myers CM. Practice Guidelines for Acute Care Nurse Practitioners-E-Book: Elsevier Health Sciences 2007.

[20] Walker SN, Kerr MJ, Pender NJ, et al. A Spanish language version of the health-promoting lifestyle profile. Nursing Research 1990;39(5):268-73.

[21] Kamrani F, Nikkhah S, Borhani F, et al. The effect of patient education and nurse-led telephone follow-up (telenursing) on adherence to treatment in patients with acute coronary syndrome. 2015.

[22] Shojaee A, Nehrir B, Naderi N, et al. Effect of patient education and telephone follow up by the nurse on the level of hope in patients suffering from heart failure. Journal of Nursing Education 2013;2(3):16-26.

[23] Fakharzadeh L, Shahbazian H, Salehinia H, et al. Effect of telenursing on glycosylated hemoglobin (HbA1c) and anthropometric indexes in type 2 diabetic patients. Modern Care Journal 2013;10(2):101-7.

[24] Kotb A, Hsieh S, Wells GA. The effect of telephone support interventions on coronary artery disease (CAD) patient outcomes during cardiac rehabilitation: a systematic review and meta-analysis. PLoS One 2014;9(5):e96581.

[25] Behzad Y, Bastani F, Haghani H. Effect of empowerment program with the telephone follow-up (tele-nursing) on self-efficacy in self-care behaviours in hypertensive older adults. The Journal of Urmia Nursing and Midwifery Faculty 2016;13(11):1004-15.

[26] Baraz SH, Mohammadi E, Boroumand B. A comparative study on the effect of two methods of self-care education (direct and indirect) on quality of life and physical problems of haemodialysis patients. Arak Med Univ J (AMUJ) 2006;9(1):7-22.

[27] Wong FK, Chow SK, Chan TM, et al. Comparison of effects between home visits with telephone calls and telephone calls only for transitional discharge support: a randomised controlled trial. Age and Ageing 2014;43(1):91-7. 